\title{
Estrogen receptor beta gene variants are associated with increased risk of Alzheimer's disease in women
}

\author{
Mia Pirskanen ${ }^{1}$, Mikko Hiltunen ${ }^{1,2}$, Arto Mannermaa ${ }^{3}$, Seppo Helisalmi ${ }^{1,2}$, \\ Maarit Lehtovirta $^{4,5}$, Tuomo Hänninen ${ }^{4}$ and Hilkka Soininen*,1,2,4
}

${ }^{1}$ Department of Neuroscience and Neurology, University of Kuopio, Finland; ${ }^{2}$ Brain Research Unit, Clinical Research Centre/Mediteknia, University of Kuopio, Finland; ${ }^{3}$ Department of Clinical Pathology and Forensic Medicine, University of Kuopio, Finland; ${ }^{4}$ Department of Neurology, University Hospital of Kuopio, Finland; ${ }^{5}$ Department of Neurology, Jorvi Hospital, Espoo, Finland

We investigated the association of five intronic single-nucleotide polymorphism (SNP) at the estrogen receptor beta (ESR2) gene locus and the susceptibility of developing Alzheimer's disease (AD) in 387 subjects with clinically diagnosed probable $A D$ and 467 cognitively normal individuals derived from eastern Finland. According to our results, variation in the ESR2 gene is associated with an increased risk of $A D$ in women, whereas it does not contribute to the disease susceptibility in men. More specifically, in women, the allele T and the genotype T/T of two of the studied ESR2 gene SNPs (SNP2 and SNP3) were more frequent in $A D$ women than in cognitively normal control women $(P=0.012$ and $P=0.016$, respectively). The ESR2 SNP2 T/T genotype and the SNP3 T/T genotype were associated with a significant, nearly two-fold increase in the risk of $A D$ in women $(O R=1.87,95 \% \mathrm{Cl}=1.21-2.90)$, and remained significant after adjustment with the APOE genotype and age $(\mathrm{OR}=1.63,95 \% \mathrm{Cl}, 1.00-1.68)$. The combined effect of the ESR2 SNP2 T/T or SNP3 T/T genotype and female gender increases the risk of the disease $(\mathrm{OR}=3.2,95 \% \mathrm{Cl}=1.3-7.7)$. Consistent with these results, also the frequency of the haplotype containing the two above ESR2 gene risk alleles was elevated in AD women $(P=0.027$, OR $=1.3,95 \%$ $\mathrm{Cl}=1.02-1.65)$. Results show that variation in ESR2 gene may be linked with increased AD susceptibility and furthermore, this association is gender specific.

European Journal of Human Genetics (2005) 13, 1000-1006. doi:10.1038/sj.ejhg.5201447;

published online 8 June 2005

Keywords: Alzheimer's disease; association; estrogen receptor beta gene; gender; haplotype; single-nucleotide polymorphism

\section{Introduction}

Alzheimer's disease (AD) is the most common type of dementia among the aged population. Thus far the only well-established genetic risk factor for late onset $\mathrm{AD}$ is the $\varepsilon 4$ allele of the APOE gene (apolipoprotein E). A number

${ }^{*}$ Correspondence: Professor H Soininen, Department of Neuroscience and Neurology, University of Kuopio, Harjulantie 2 D, PO Box 1627, 70210 Kuopio, Finland. Tel: + 358 (0)17 173012;

Fax: + 358 (0)17 173019; E-mail: Hilkka.Soininen@uku.fi

Received 27 July 2004; revised 13 April 2005; accepted 26 April 2005; published online 8 June 2005 of studies have, however, predicted the existence of other late onset $\mathrm{AD}$ genes in addition to APOE. ${ }^{1,2}$ Also, the results from our previous genome wide association study pointed to the presence of several chromosomal loci linked with the risk of late onset $\mathrm{AD} .^{3}$ One of those areas is located in chromosome $14 \mathrm{q} 22$ and contains a putative candidate gene that may be involved in the development of $\mathrm{AD}$, namely the estrogen receptor beta gene (ESR2).

Estrogens have an important role in maintaining neural functions and in protection against damage in the normal adult brain (for reviews, see McEwen and Alves, ${ }^{4}$ GarciaSegura et $a l,{ }^{5}$ Norbury et $a l^{6}$ and Wise et $a l^{7}$ ). Estrogens 
promote neuronal cell survival and offer protection against neurotoxins. They facilitate axonal sprouting and neuronal repair, reduce neuronal injury and enhance synaptic transmission and neurogenesis. They may also regulate and influence mood, memory and cognition. ${ }^{8,9}$ These beneficial effects have led to the proposal that estrogens may also exert protective actions against neurodegenerative diseases, such as AD. The protective effects of estrogens have been detected in many epidemiological studies, which have led to proposal that estrogen replacement therapy may reduce the risk and severity of $\mathrm{AD} .^{10-12}$ Moreover, it might be speculated that the higher prevalence of $\mathrm{AD}$ in women when compared to men ${ }^{13,14}$ is due to estrogens. However, more studies are still needed to address the role of estrogens in the prevention, treatment and risk of $\mathrm{AD}$ since conflicting results have also been reported recently. ${ }^{15-17}$ Nevertheless, estrogen derivatives may still be plausible candidates in the development of treatment strategies for AD.

One mechanism by which estrogens exert their protective effects in brain is through estrogen receptors. Currently, two estrogen receptor genes have been identified in humans: the original ESR1 (estrogen receptor alpha) and the more recently found receptor, ${ }^{18}$ ESR2 (estrogen receptor beta), located on chromosome $14 \mathrm{q} 22-24 .^{19,20}$ Estrogen receptors are ligand-activated transcription factors located mainly in the cell nucleus. They mediate the effects of estrogens by binding specific DNA sequences called estrogen response elements present in the promoter regions or enhancers of target genes and subsequently regulate their transcription. ${ }^{21}$ In the brain, the genes that estrogens regulate via their cognate receptors are thought to include apoptotic/antiapoptotic genes, neurotrophins and growth factors, and genes that mediate structural alterations in neurons and synaptogenesis. ${ }^{7}$ Variation in both of these estrogen receptor genes has been linked with altered risk of AD in some, ${ }^{22-24}$ but not in all, studies. ${ }^{25}$ Estrogen receptors have also been introduced to serve as candidates for therapeutic approaches aimed at protecting the brain from age-related neurodegeneration. ${ }^{26,27}$

Based on the biochemical link between estrogens, their cognate receptors and $\mathrm{AD}$ and, importantly, due to our results from a previous study pointing to the presence of an AD-associated risk gene at this locus $(14 q 22-24),{ }^{3}$ we wanted to investigate whether variation in ESR2 is genetically associated with the risk of $\mathrm{AD}$. We did this by investigating five single-nucleotide variant (SNPs) sites of the ESR2 gene among $387 \mathrm{AD}$ patients and 467 cognitively normal controls derived from eastern Finland. Moreover, since the prevalence of $\mathrm{AD}$ is higher in women when compared to men, ${ }^{13,14}$ and that this difference may be due to estrogens, we wanted to evaluate whether there would be a difference in the AD risk associated with these ESR2 gene variants between men and women. Our results show that ESR2 loci may harbor genetic variants that are linked with increased vulnerability to $\mathrm{AD}$ in a gender-specific manner.

\section{Subjects and methods Subjects}

This study is a part of an ongoing project aimed at identifying risk genes for $\mathrm{AD}$ being conducted in the Kuopio University and the University Hospital of Kuopio, Finland. The Ethics Committee of the Kuopio University Hospital and Kuopio University approved this study. The subjects were derived from longitudinal studies into ageing and dementia being conducted in the Kuopio Alzheimer Center. $^{28}$ All of the participants or caregivers of the demented patients provided informed consent.

This study included a total of 854 unrelated subjects, of which 387 were AD patients (116 men, 271 women) and 467 were nondemented control individuals (185 men, 282 women), derived from the same geographic area in eastern Finland. The age (mean \pm SD) at onset was $71.8 \pm 7.1$ years (range 43-90) for $\mathrm{AD}$ and for controls the age when sampled was $69.6 \pm 5.1$ years (range 60-87). In women, these ages were $72.1 \pm 7.1$ years in $\mathrm{AD}$ and $70.2 \pm 5.0$ years in controls and in men $71.0 \pm 7.2$ years in $\mathrm{AD}$ and $68.8 \pm 5.1$ years in controls. The ages differed significantly between $\mathrm{AD}$ patients and control in all of the above-mentioned groups $(P<0.05)$.

The 467 controls were cognitively normal volunteers. Their cognitive status was examined using Mini Mental State Examination (mean MMSE $\pm S D, 27.0 \pm 1.4$ ) or a neuropsychological test and the test results showed no signs of dementia. Of the $387 \mathrm{AD}$ patients, 352 had a clinical diagnosis of probable $\mathrm{AD}$ according to the NINCDS-ADRDA criteria. ${ }^{29}$ All AD patients had undergone a thorough investigation, which included a medical history, physical, neurological and neuropsychological examination (mean MMSE \pm SD, 17.2 \pm 7.0 ), and routine laboratory tests to exclude other causes of dementia, as well as computed tomography (CT) scan or magnetic resonance imaging (MRI) of the brain. The remaining 35 patients in the AD group had in addition to the clinical diagnosis also a neuropathological confirmation of $\mathrm{AD}$ pathology according to neuropathological CERAD criteria for $\mathrm{AD} .^{30}$

\section{SNP selection}

Originally we selected 10 SNP sites from the dbSNP database, which covered the ESR2 gene. The heterozygosity of the selected variants in our population was investigated from 30 DNA samples, which we deemed to be high enough number to estimate the crude allele frequencies of these ESR2 SNPs (data not shown). This revealed that six of the SNPs were not informative enough for this study (minor allele frequency, MAF <0.1). When the selected 


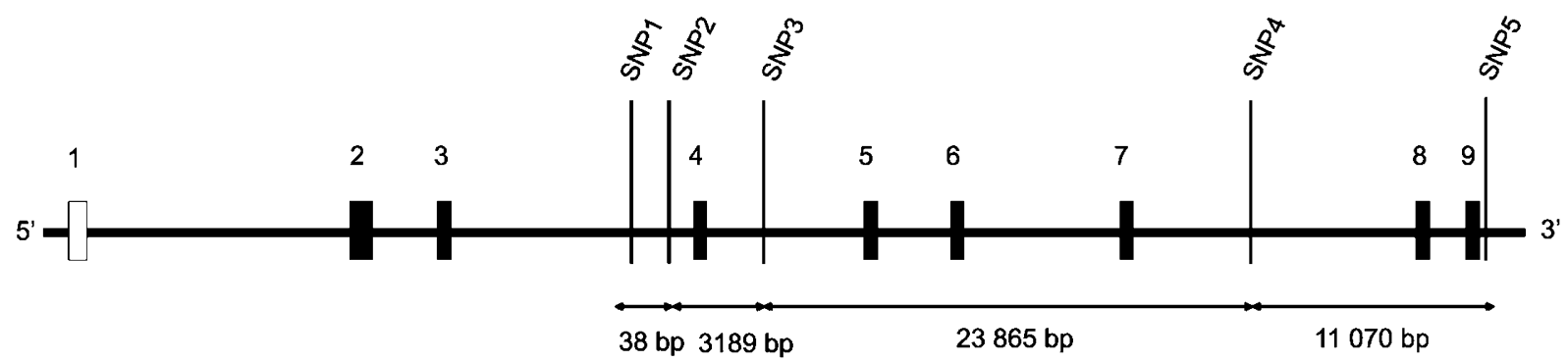

Figure 1 Schematic view of the ESR2 gene and the location of the five intragenic single-nucleotide variant sites (SNPs) investigated in the current study. White box represents the untranslated first exon, and black boxes (2-9) represent the coding exons. The distance between adjacent SNPs is marked under the arrow headed lines in base pairs (bp). The distance between the first and the last ESR2 gene exon is approximately 61200 bp. SNP descriptions are as follows (National Center for Biotechnology Information SNP cluster rsID numbers shown in parenthesis if available); SNP1 = IVS3$1842 \mathrm{~A}>\mathrm{G}$ (not available), SNP2 $=$ IVS3-1880C $>$ T (rs1271573), SNP3 = IVS4 + 1231C > T (rs1256043), SNP4 =IVS7 + 5847C $>$ T (rs1256059) and SNP5 $=3^{\prime} U^{\prime} R^{*} 39 A>C$ (rs4986938).

variant sites were confirmed by sequencing, the data revealed an additional SNP (SNP1 in this study), not originally detected in the dbSNP database and this SNP was also included in the study. The selected SNPs (SNPs 1-5) and their descriptions are presented in Figure 1.

\section{Methods}

The five studied SNP sites (SNPs 1-5, Figure 1) were amplified in three separate polymerase chain reactions (PCR) using a PCR machine (MJ Research, Inc., Waltham, MA, USA). The PCR for all of the reactions was $2 \mathrm{~min}$ at $95^{\circ} \mathrm{C}, 35 \times\left(30 \mathrm{~s}\right.$ at $94^{\circ} \mathrm{C}, 30 \mathrm{~s}$ at $53-66^{\circ} \mathrm{C}, 30 \mathrm{~s}$ at $\left.72^{\circ} \mathrm{C}\right)$ and $5 \mathrm{~min}$ at $72^{\circ} \mathrm{C}$. The PCR primer pair sequences were (SNP1 and 2) $5^{\prime}$-atg ctg caa caa aca tgg aag t-3 $3^{\prime}$ and $5^{\prime}$-gtg ttg gcc agt ctg gtc tc- $3^{\prime}$, (SNP3) $5^{\prime}$-agc cct ccc tga caa ttt ctt a-3' and $5^{\prime}$-gca ctg gca gga tgt tct aca g-3', (SNP4) 5'-tga ctc taa tgc cag tct ctt cc- $3^{\prime}$ and $3^{\prime}$-ctc tac tct tga gct ttg tgc tg- $3^{\prime}$, (SNP5) $5^{\prime}$-ttt ttg tcc cca tag taa ca-3' and 5'-aat gag gga cca cag ca-3'. The PCR mixture contained $25 \mathrm{ng}$ human genomic DNA (extracted from peripheral blood), $1 \times$ PCR Buffer (AmpliTagGold, Applied Biosystems, Foster City, CA, USA), $200 \mu \mathrm{M}$ of each of the nucleotides (dATP, dCTP, dGTP, dTTP, Finnzymes, Espoo, Finland), $0.5 \mu \mathrm{M}$ of each primers and $1 \mathrm{U}$ of the DNA polymerase (AmpliTagGold, Applied Biosystems) and was adjusted with $\mathrm{dH}_{2} \mathrm{O}$ to the final volume of $10 \mu \mathrm{l}$.

The samples were genotyped with the Snapshot method (Applied Biosystem). In all, $3 \mu$ l of each of the three PCR products were pooled and purified with SAP (2.5 U, Shrimp Alkaline Phosphatase, USB Corporation, Cleveland, $\mathrm{OH}$, USA) and ExoI (Exonuclease I, New England BioLabs, Inc., MA, USA) treatment at $37^{\circ} \mathrm{C}$ for $1 \mathrm{~h}$ and at $75^{\circ} \mathrm{C}$ for $15 \mathrm{~min}$. In total, $4 \mu \mathrm{l}$ of purified PCR products, $1.25 \mu \mathrm{l}$ of Snapshot Multiplex Ready Reaction Mix (Applied Biosystems), $0.1 \mu \mathrm{l}$ of pooled extension primers (10 pmol $/ \mu \mathrm{l}$ each) and $3.75 \mu \mathrm{l}$ of Tris-HCl $(10 \times$ ABI Buffer, Applied Biosystems $)$ were mixed in a tube and adjusted with $\mathrm{dH}_{2} \mathrm{O}$ to the final volume of $10 \mu \mathrm{l}$. The Extension primer sequences were (SNP1) 5'-45(t) tct ggc cag ctg tgg tgg ctc-3', (SNP2) 5'-24(t) ctt tgg gag acc aag gcg gg-3', (SNP3) 5'-32(t) aaa ggg cag aga atg ctc ac-3', (SNP4) $5^{\prime}-51(\mathrm{t})$ taa ggc tga gaa gtg ccc aat-3' and (SNP5) $5^{\prime}-40(\mathrm{t}) \mathrm{ctg}$ gag ttc acg ctt cag c-3'. The reaction was subjected to 45 cycles of the following steps: $10 \mathrm{~s}$ at $96^{\circ} \mathrm{C}, 5 \mathrm{~s}$ at $50^{\circ} \mathrm{C}$ and $30 \mathrm{~s}$ at $60^{\circ} \mathrm{C}$ in a PCR machine (MJ Research). One unit of SAP was added to the reactions and incubated $\left(1 \mathrm{~h}\right.$ at $37^{\circ} \mathrm{C}, 15 \mathrm{~min}$ at $\left.75^{\circ} \mathrm{C}\right)$. In all, $0.5 \mu \mathrm{l}$ of the Snapshot products, $9.00 \mu \mathrm{l} \mathrm{Hi}-\mathrm{Di}$ formamide (Applied Biosystems) and $0.25 \mu \mathrm{l}$ size standard (GeneScan-120 LIZ, Applied Biosystems) were pooled, denatured at $95^{\circ} \mathrm{C}$ for 5 min and loaded onto an ABI Prism 3100 Genetic Analyzer (Applied Biosystems). Electrophoresis data were processed and the genotypes were visualized by using the GeneScan Analysis version 3.7 (Applied Biosystems) and the Genotyper program (Applied Biosystems). APOE genotypes were determined as described previously. ${ }^{31}$

\section{Statistics}

Chi-squared $\left(\chi^{2}\right)$ statistics with Fisher's Exact Test values was used to compare the APOE and ESR2 genotype and allele frequencies between cases and controls and to calculate the odds ratios (ORs) with 95\% confidence intervals (CIs). Logistic regression analysis was used for the adjustment of ESR2 genotypes with age and APOE. The Mann-Whitney $U$ test was used to compare the age differences between $\mathrm{AD}$ and control groups. The analysis was performed using the SPSS for Windows release 10.0. The estimation of haplotype frequencies was performed with Arlequin version 2.0 (http://lgb.unige.ch/arlequin/). Pair-wise linkage disequilibrium (LD) of SNPs was determined using the 2LD program (http://www.iop.kcl.ac.uk/ IoP/Departments/PsychMed/GepiBSt/software.shtml).

Haplotype frequencies were compared for case and control subjects using the RxC-program employing the metropolis algorithm to obtain unbiased estimates for exact $P$-values with standard errors. ${ }^{32}$ The level of statistical significance was set at $P<0.05$ for each analysis. 


\section{Results}

As expected, the APOE $\varepsilon 4$ allele was present significantly more frequently in the $\mathrm{AD}$ group when compared to controls. The APOE $\varepsilon 2 / \varepsilon 3 / \varepsilon 4$ allele frequencies were $0.04 /$ $0.80 / 0.16$ in controls and $0.02 / 0.56 / 0.42$ in $\mathrm{AD}$, respectively $\left(\chi^{2}=151.6, P<0.001\right)$ and the OR associated with AD for carrying at least one copy of the APOE $\varepsilon 4$ allele was 7.1 $\left(\chi^{2}=175.5, P<0.001,95 \%\right.$ CI 5.3-9.3) when compared to subjects with no APOE $\varepsilon 4$ allele. The APOE genotypes were distributed according to Hardy-Weinberg equilibrium (HWE) both in $\mathrm{AD}$ and control groups.

Five ESR2 gene SNPs were genotyped and investigated in the study material (Figure 1). Four of the studied ESR2 variants were in HWE both in the $\mathrm{AD}$ and control groups. One SNP (SNP4), however, was not able to fulfil the HWE either in the $\mathrm{AD}$ or control group and therefore it was excluded from further analysis. To determine whether the remaining four ESR2 variants were associated with $\mathrm{AD}$, we initially compared the single-point ESR2 genotype and allele distributions between AD patients and cognitively normal controls in our whole study material. This comparison showed that the ESR2 genotype and allele distributions did not generally differ between AD patients and controls $(P>0.05$, Table 1$)$.
Stratification according to the gender revealed a statistically significant difference in ESR2 genotype and allele frequencies between $\mathrm{AD}$ patients and controls in women (Table 1). According to the results, the ESR2 gene SNP2 genotype $\mathrm{T} / \mathrm{T}$ and the SNP3 genotype $\mathrm{T} / \mathrm{T}$ were more frequent in women with $\mathrm{AD}$ than in cognitively normal women (uncorrected $P$-value $=0.016$, Bonferroni corrected $P$-value 0.192). Also, the frequencies of the ESR2 gene SNP2 allele $\mathrm{T}$ and the SNP3 allele $\mathrm{T}$ were elevated in female patients (uncorrected $P$-value $=0.012 ， \quad O R=1.4 ， \quad 95 \%$ $\mathrm{CI}=1.1-1.7$, Bonferroni corrected $P$-value $=0.144$, $).$ In men, on the other hand, the studied ESR2 gene variations were not linked with any increased susceptibility to the disease (Table 1).

To define the level of risk, logistic regression models were applied to estimate the relative risk of $\mathrm{AD}$ related to the different ESR2 genotypes (Table 2). This analysis showed that ESR2 SNP2 T/T and the SNP3 T/T genotypes were associated with a nearly 1.9-fold increase in the risk of AD in women. Adjustment by the APOE and age diminished the risk but the association still remained significant (Table 2). When analyzing the combined effect of women gender and at least one $\mathrm{T}$ allele, the logistic regression analysis resulted in an $\mathrm{OR}$ of $2.7(\mathrm{CI}=1.2-6.0)$. The

Table 1 The genotype and allele frequencies of the studied estrogen receptor beta (ESR2) single-nucleotide variant sites (SNPs 1-3 and 5) in Alzheimer's disease patients (AD) and controls in all subjects and in women and men

\begin{tabular}{|c|c|c|c|c|c|c|c|c|c|c|c|c|}
\hline $\begin{array}{l}\text { Studied SNP } \\
\text { genotype/allele }\end{array}$ & $\begin{array}{c}A D \\
(N=387)\end{array}$ & $\begin{array}{l}\text { All subjects } \\
\text { Controls } \\
(N=467)\end{array}$ & $\chi^{2}$ & $P$ & $\begin{array}{c}A D \\
(N=271)\end{array}$ & $\begin{array}{c}\text { Women } \\
\text { Controls } \\
(N=282)\end{array}$ & $\chi^{2}$ & $P$ & $\begin{array}{c}A D \\
(N=116)\end{array}$ & $\begin{array}{c}\text { Men } \\
\text { Controls } \\
(N=185)\end{array}$ & $\chi^{2}$ & $P$ \\
\hline \multicolumn{13}{|l|}{ SNP1 } \\
\hline $\mathrm{AA}$ & $4(0,01)$ & $5(0,01)$ & & & $3(0,01)$ & $3(0,01)$ & & & $1(0,01)$ & $2(0,01)$ & & \\
\hline AG & $56(0,15)$ & $86(0,18)$ & 2.391 & 0.303 & $41(0,15)$ & $56(0,20)$ & 2.1 & 0.34 & $15(0,13)$ & $30(0,16)$ & 0.7 & 0.72 \\
\hline GG & $327(0,84)$ & $376(0,81)$ & & & $227(0,83)$ & $223(0,80)$ & & & $100(0,86)$ & $153(0,83)$ & & \\
\hline A & $64(0,08)$ & $96(0,10)$ & & & $47(0,09)$ & $62(0,11)$ & & & $17(0,07)$ & $34(0,09)$ & & \\
\hline G & $710(0,92)$ & $838(0,90)$ & 2.01 & 0.156 & $495(0,91)$ & $502(0,89)$ & 1.676 & 0.195 & $215(0,93)$ & $336(0,91)$ & 0.637 & 0.425 \\
\hline \multicolumn{13}{|l|}{ SNP2 } \\
\hline $\mathrm{CC}$ & $123(0,32)$ & $156(0,33)$ & & & $83(0,31)$ & $102(0,36)$ & & & $40(0,35)$ & $54(0,29)$ & & \\
\hline CT & $185(0,48)$ & $238(0,51)$ & 3.316 & 0.191 & $124(0,46)$ & $140(0,50)$ & 8.2 & $0.016^{*}$ & $61(0,52)$ & $98(0,53)$ & 1.7 & 0.42 \\
\hline TT & $79(0,20)$ & $73(0,16)$ & & & $64(0,23)$ & $40(0,14)$ & & & $15(0,13)$ & $33(0,18)$ & & \\
\hline C & $431(0,56)$ & 550 & & & $290(0,53)$ & $344(0,61)$ & & & $141(0,61)$ & $206(0,56)$ & & \\
\hline $\mathrm{T}$ & $3(0,44)$ & $384(0,41)$ & 1.775 & 0.183 & $252(0,47)$ & $220(0,39)$ & 6.334 & $0.012^{*}$ & $91(0,39)$ & $164(0,44)$ & 1.519 & 0.218 \\
\hline \multicolumn{13}{|l|}{ SNP3 } \\
\hline $\mathrm{CC}$ & $123(0,32)$ & $156(0,33)$ & & & $83(0,31)$ & $102(0,36)$ & & & $40(0,35)$ & $54(0,29)$ & & \\
\hline CT & $185(0,48)$ & $238(0,51)$ & 3.316 & 0.191 & $124(0,46)$ & $140(0,50)$ & 8.2 & $0.016^{*}$ & $61(0,52)$ & $98(0,53)$ & 1.7 & 0.42 \\
\hline TT & $79(0,20)$ & $73(0,16)$ & & & $64(0,23)$ & $40(0,14)$ & & & $15(0,13)$ & $33(0,18)$ & & \\
\hline C & $431(0,56)$ & $550(0,59)$ & & & $290(0,5$ & $344(0,61)$ & & & $141(0,61)$ & $206(0,56)$ & & \\
\hline $\mathrm{T}$ & $343(0,44)$ & $384(0,41)$ & 1.775 & 0.183 & $252(0,47)$ & $220(0,39)$ & 6.334 & $0.012^{*}$ & $91(0,39)$ & $164(0,44)$ & 1.519 & 0.218 \\
\hline \multicolumn{13}{|l|}{ SNP5 } \\
\hline GG & $147(0,38)$ & $192(0,41)$ & & & $112(0,41)$ & $116(0,41)$ & & & $35(0,3$ & $76(0,41)$ & & \\
\hline GA & $185(0,48)$ & $205(0,44)$ & 1.316 & 0.518 & $126(0,47)$ & $123(0,44)$ & 1.2 & 0.55 & $59(0,51)$ & $82(0,44)$ & 3.8 & 0.15 \\
\hline AA & $55(0,14)$ & $70(0,15)$ & & & $33(0,12)$ & $43(0,15)$ & & & $22(0,19)$ & $27(0,15)$ & & \\
\hline G & $479(0,62)$ & $589(0,63)$ & & & $350(0,65)$ & $355(0,63)$ & & & $129(0,56)$ & $234(0,63)$ & & \\
\hline A & $295(0,38)$ & $345(0,37)$ & 0.25 & 0.617 & $192(0,35)$ & $209(0,37)$ & 0.319 & 0.572 & $103(0,44)$ & $136(0,37)$ & 3.477 & 0.062 \\
\hline
\end{tabular}

Statistically significant results denoted with an asterisk $\left({ }^{*}\right)$. 
Table 2 Estimated ORs for the studied SNP genotypes in women obtained from logistic regression analyses

\begin{tabular}{llcr}
\hline SNP & $\begin{array}{c}\text { Compared } \\
\text { genotypes }\end{array}$ & $\begin{array}{c}\text { OR }(95 \% \mathrm{Cl}), \begin{array}{c}\text { Univariate } \\
\text { logistic regression }(N=553)\end{array} \\
\text { OR (95\% CI), adjusted for age } \\
\text { and } A P O E(N=553)\end{array}$ \\
\hline SNP1 & AA+AG versus GG & $1.37,(0.89-2.10), P=0.16$ & $1.42,(0.87-2.34), P=0.16$ \\
SNP2 & CC+CT versus TT & $1.87,(1.21-2.90), P=0.005$ & $1.63,(1.00-2.68), P=0.05$ \\
SNP3 & CC+CT versus TT & $1.87,(1.21-2.90), P=0.005$ & $1.63,(1.00-2.68), P=0.05$ \\
SNP5 & AA+GA versus GG & $1.01,(0.72-1.41), P=0.96$ & $0.88,(0.60-1.30), P=0.52$ \\
\hline
\end{tabular}

$\mathrm{SNP}=$ single nucleotide polymorphism; $\mathrm{OR}=$ odds ratio.

Table 3 The estimated estrogen receptor beta (ESR2) gene haplotype frequencies and odds ratios for the haplotypes in women

\begin{tabular}{lrrrr}
\hline Haplotype & $A D(N=542)$ & Control $(\mathrm{N}=564)$ & $P_{\text {-value }}^{\mathrm{a}}$ & ${\text { Odds ratio }(95 \% \mathrm{Cl})^{\mathrm{b}}}$ \\
\hline H1 (A-C-C-G) & $47(0.087)$ & $61(0.108)$ & $0.247 \pm 0.007$ & $0.78(0.53-1.17)$ \\
H2 (G-C-C-G) & $60(0.111)$ & $76(0.135)$ & $0.224 \pm 0.010$ & $0.80(0.56-1.15)$ \\
H3 (G-C-C-A) & $183(0.338)$ & $207(0.367)$ & $0.322 \pm 0.015$ & $0.88(0.69-1.13)$ \\
H4 (G-T-T-G) & $243(0.448)$ & $217(0.385)$ & $0.027 \pm 0.009$ & $1.30(1.02-1.65)$ \\
H5 (Others) & $9(0.017)$ & $3(0.005)$ & $0.085 \pm 0.002$ & $3.16(0.85-11.73)$ \\
Overall & & & $0.048 \pm 0.007$ & \\
\hline
\end{tabular}

${ }^{\text {a }} P$-values calculated by using RxC program ( \pm standard error).

${ }^{b}$ Odds ratios with $95 \%$ confidence intervals ( $95 \% \mathrm{Cls}$ ) were calculated by comparing, for example, haplotype $\mathrm{H} 1$ to pooled other haplotypes. For the calculations, Fisher's Exact Test was used.

combined effect was most significant in the women carrying two $\mathrm{T}$ alleles $(\mathrm{OR}=3.2, \mathrm{CI}=1.3-7.7)$.

We also performed an association analysis between $\mathrm{AD}$ patients and controls by using the five estimated haplotypes constructed from the ESR2 genotype data. This analysis did not reveal any association in either overall or single haplotype level among the whole material $(P>0.05$, data not shown) or in men $(P>0.05$, data not shown), whereas ESR2 haplotype frequencies deviated significantly between AD patients and controls in women (Table 3, uncorrected $P$-value $=0.048$, Bonferroni corrected $P$ value $=0.096$ ). Importantly, the haplotype $H 4$, which contained the above-mentioned risk alleles T (SNP2) and $\mathrm{T}$ (SNP3), was more frequent in women with $\mathrm{AD}$ than in control women (uncorrected $P$-value $=0.027$, Bonferroni corrected $P$-value $=0.405)$.

The genotypic disequilibrium values for all the comparisons were highly significant for all SNP locus pairs across all populations as well as separately in the AD and control groups $(P<0.000001)$.

\section{Discussion}

We tested the association between the polymorphism in ESR2 gene and late onset AD and found that variation in the ESR2 gene could modify disease susceptibility. We performed an association analysis by using the allele, genotype and haplotype data from four ESR2 gene SNPs and could consistently show that variation in the ESR2 gene was linked with increased $\mathrm{AD}$ risk in women in our study sample. This association, however, was not seen in the whole study material or in men.

The lack of association between variation in ESR2 gene and $\mathrm{AD}$ in men indicates that the variation in the ESR2 gene may pose a gender-specific risk for the disease and is linked with an increased $\mathrm{AD}$ risk in women only. The reason for this finding remains unclear, but there is a sex difference in the incidence of $\mathrm{AD}$, with women being more prone compared to men, ${ }^{13,14}$ and thus it could be speculated that sex steroids, such as estrogens and the genes in the estrogen response cascades (ie estrogen receptors) might be involved in the AD pathophysiology in women. According to the same line of thought, since estrogens exert their effects partly via estrogen receptors, a genetic variation in the ESR2 could also have a sex-specific role in $\mathrm{AD}$ risk.

In a previous case-control study, variation in the CA repeat in intron 5 of the ESR2 gene was linked with susceptibility to suffer $\mathrm{AD}$ but on the contrary to our present results, a protective effect of ESR2 in AD, especially in men, was proposed. ${ }^{24}$ In our study, the ESR2 genotype was linked with an increased risk of AD in women but we could not find any evidence for a contribution of the studied ESR2 gene variants to the risk of $\mathrm{AD}$ in men. It is possible that the different ethnic background and the smaller sample size in the previous study may account for the discrepancy in the results between the current and the previous study. Differences could also be attributable to the faster mutation rate of a microsatellite markers compared 
to SNPs. This, on the other hand, decays LD between a microsatellite and a disease locus more rapidly than between SNP and disease locus and therefore it is not possible to draw direct conclusions between the current and the previous studies. The association of the SNP rs_4986938 (SNP5 in our study) with AD has been investigated also previously in a case-control study, but in line with our results this ESR2 gene SNP showed no independent association with the risk of developing $\mathrm{AD}$ in the total sample nor separately for either gender. ${ }^{33}$

The genetic variants that we tested lie in the introns or untranslated regions of the ESR2 gene and therefore it is unlikely that they represent pathological variants themselves. Rather, they may be marker alleles in linkage disequilibrium with a mutation elsewhere within or in the vicinity of the studied gene. The ESR2 gene consists of nine exons. The SNPs that were associated with AD in the current study (SNP2 and SNP3) lie in introns 3 and 4 of the ESR2 gene, respectively. The SNP5, which showed no association with the disease, on the other hand, lie in the $3^{\prime}$ untranslated region of the gene. This could indicate that the $5^{\prime}$ end of the ESR2 gene might harbor alleles that are related with an elevated risk of AD. SNP1, on the other hand, was the SNP closest to the $5^{\prime}$ end of the gene but it did not appear to be involved with increased disease susceptibility. This could be due to the low minor allele frequency $(\mathrm{MAF}=0.1)$ of this marker. Therefore, perhaps a larger sample size would have been necessary to reveal the possible association between SNP1 and AD. In the case of SNP5, which showed a minor allele frequency similar to SNPs 2 and 3 (0.38 versus 0.44 , respectively), it is more difficult to explain the lack of association between this marker and AD, bearing in mind that all of the SNPs were in tight LD with each other. However, it is possible that despite the tight LD between the studied ESR2 SNPs, the SNP5 is a part of some haplotype block other than the SNPs 2 and 3.

While the role of estrogens in prevention and treatment of $\mathrm{AD}$ is a matter of intense debate, experimental evidence do indicate that estrogens possess neuroprotective effects, are critical to cognitive function and may also be involved in neuronal disorders including AD. Although the specific functions of ESR2 in brain are unclear, there is evidence to suggest that ESR2 is linked with estrogen-induced neuroprotective effects and also to AD pathophysiology. Firstly, ESR2 is present in the hippocampal formation and entorhinal and temporal cortex and therefore this receptor might regulate gene transcription in neuronal populations important in cognition and memory. ${ }^{34}$ Secondly, ESR2 has been reported to be necessary for neuronal survival and therefore could have an influence on the development of AD. ${ }^{26}$ Moreover, ESR2 is required in estrogen-mediated neuroprotection against $\mathrm{AD}$-related beta-amyloid ${ }^{35}$ and glutamate toxicity ${ }^{36,37}$ and it has been linked with ADrelated neuropathological changes. ${ }^{38,39}$ Also, variation in the other estrogen cascade gene, ESR1, has been previously linked with increased risk of AD in some, ${ }^{22,23}$ but not all, studies. ${ }^{25,33}$ Thus, based on the evidence mentioned above, it could be speculated that a genetic defect affecting ESR2 gene could account for the increased vulnerability to develop $\mathrm{AD}$. Other mechanisms also exist which could explain the link between ESR2 and AD found in the current study. For example, genetic and molecular biology studies concerning ESR2 have associated the gene with elevated blood pressure, ${ }^{40,41}$ a disease which has been linked with increased susceptibility to AD. ${ }^{42}$

In conclusion, we detected an association of the ESR2 gene and $\mathrm{AD}$ with a reliable number of carefully clinically evaluated $\mathrm{AD}$ patients and controls and found that the ESR2 genotype increases the risk of the disease in women. More specifically, women carrying two T alleles were over three times more prone to develop AD when compared to subjects with no T allele in the ESR2 gene SNP2 or SNP3 locus. Although the association found in this study was not a general phenomenon in our material, but was restricted to women patients only, the finding fits well to the view where estrogen, and perhaps also its cognate receptors, such as ESR2, most likely have a role in the risk of AD in women. However, these results have to be interpreted with caution since further studies using sufficient number of subjects from different populations as well as identifying the possible causative sequence alteration and its function at the genomic level are still needed to extend and confirm the role of ESR2 in AD. Nonetheless, this study supports the possible role of ESR2 as a potential target for therapeutic approaches that might be efficient in protecting the brain from age-related neurodegeneration.

\section{Acknowledgements}

We thank Mrs Marjo Laitinen for her skilful technical help. This study was supported by the Emil Aaltonen Foundation, the Ella and Georg Ehrnrooth Foundation, the Finnish Cultural Foundation NorthSavo Foundation, the Health Research Council of the Academy of Finland, EVO grants (5772708, 5772720) of Kuopio University Hospital and the EU 5th Framework Program (Contract No QLK6-CT-1999-02112).

\section{References}

1 Daw EW, Payami H, Nemens EJ et al: The number of trait loci in late-onset Alzheimer disease. Am J Hum Genet 2000; 66: 196-204.

2 Blacker D, Bertram L, Saunders AJ et al: Results of a highresolution genome screen of 437 Alzheimer's disease families. Hum Mol Genet 2003; 12: 23-32.

3 Hiltunen M, Mannermaa A, Thompson D et al: Genome-wide linkage disequilibrium mapping of late-onset Alzheimer's disease in Finland. Neurology 2001; 57: 1663-1668.

4 McEwen BS, Alves SE: Estrogen actions in the central nervous system. Endocr Rev 1999; 20: 279-307.

5 Garcia-Segura LM, Azcoitia I, DonCarlos LL: Neuroprotection by estradiol. Prog Neurobiol 2001; 63: 29-60. 
6 Norbury R, Cutter WJ, Compton J et al: The neuroprotective effects of estrogen on the aging brain. Exp Gerontol 2003; 38: $109-117$.

7 Wise PM, Dubal DB, Wilson ME, Rau SW, Liu Y: 2001 Estrogens: trophic and protective factors in the adult brain. Front Neuroendocrinol 2001; 22: 33-66.

8 McEwen BS, Alves SE, Bulloch K, Weiland NG: Ovarian steroids and the brain: implications for cognition and aging. Neurology 1997; 48 (5 Suppl 7): S8-S15.

9 Fink G, Sumner BE, McQueen JK, Wilson H, Rosie R: Sex steroid control of mood, mental state and memory. Clin Exp Pharmacol Physiol 1998; 25: 764-775.

10 Waring SC, Rocca WA, Petersen RC, O'Brien PC, Tangalos EG, Kokmen E: Postmenopausal estrogen replacement therapy and risk of AD: a population-based study. Neurology 1999; 52: 965-970.

11 Baldereschi M, Di Carlo A, Lepore V et al: Estrogen-replacement therapy and Alzheimer's disease in the Italian Longitudinal Study on Aging. Neurology 1998; 50: 996-1002.

12 Tang MX, Jacobs D, Stern Y et al: Effect of oestrogen during menopause on risk and age at onset of Alzheimer's disease. Lancet 1996; 348: 429-432.

13 Gao S, Hendrie HC, Hall KS, Hui S: The relationships between age, sex, and the incidence of dementia and Alzheimer disease: a meta-analysis. Arch Gen Psychiatry 1998; 55: 809-815.

14 Andersen K, Launer LJ, Dewey ME et al: Gender differences in the incidence of $\mathrm{AD}$ and vascular dementia: the EURODEM Studies. EURODEM Incidence Research Group. Neurology 1999; 53: $1992-1997$

15 Henderson VW, Paganini-Hill A, Miller BL et al: Estrogen for Alzheimer's disease in women: randomized, double-blind, placebo-controlled trial. Neurology 2000; 54: 295-301.

16 Wang PN, Liao SQ, Liu RS et al: Effects of estrogen on cognition, mood, and cerebral blood flow in $\mathrm{AD}$ : a controlled study. Neurology 2000; 54: 2061-2066.

17 Shumaker SA, Legault C, Rapp SR et al: Estrogen plus progestin and the incidence of dementia and mild cognitive impairment in postmenopausal women: the Womeńs Health Initiative Memory Study: a randomized controlled trial. JAMA 2003; 289: 2651-2662.

18 Kuiper GG, Enmark E, Pelto-Huikko M, Nilsson S, Gustafsson JA: Cloning of a novel receptor expressed in rat prostate and ovary. Proc Natl Acad Sci USA 1996; 93: 5925-5930.

19 Enmark E, Pelto-Huikko M, Grandien K et al: Human estrogen receptor beta-gene structure, chromosomal localization, and expression pattern. J Clin Endocrinol Metab 1997; 82: 4258-4265.

20 Sand P, Luckhaus C, Schlurmann K, Gotz M, Deckert J: Untangling the human estrogen receptor gene structure. J Neural Transm 2002; 109: 567-583.

21 Kumar V, Chambon P: The estrogen receptor binds tightly to its responsive element as a ligand-induced homodimer. Cell 1988; 55: $145-156$.

22 Brandi ML, Becherini L, Gennari L et al: Association of the estrogen receptor alpha gene polymorphisms aith sporadic Alzheimer's disease. Biochem Biophys Res Commun 1999; 265: $335-338$.

23 Ji Y, Urakami K, Wada-Isoe K, Adachi Y, Nakashima K: Estrogen receptor gene polymorphisms in patients with Alzheimer's disease, vascular dementia and alcohol-associated dementia. Dement Geriatr Cogn Disord 2000; 11: 119-122.

24 Forsell C, Enmark E, Axelman K et al: Investigations of a CA repeat in the oestrogen receptor beta gene in patients with Alzheimer's disease. Eur J Hum Genet 2001; 9: 802-804.

25 Prince JA, Feuk L, Sawyer SL et al: Lack of replication of association findings in complex disease: an analysis of 15 polymorphisms in prior candidate genes for sporadic Alzheimer's disease. Eur J Hum Genet 2001; 9: 437-444.

26 Wang L, Andersson S, Warner M, Gustafsson JA: Morphological abnormalities in the brains of estrogen receptor beta knockout mice. Proc Natl Acad Sci USA 2001; 98: 2792-2796.

27 Gustafsson JA: What pharmacologists can learn from recent advances in estrogen signalling. Trends Pharmacol Sci 2003; 24: 479-485.

28 Lehtovirta $\mathrm{M}$, Soininen $\mathrm{H}$, Helisalmi $\mathrm{S}$ et al: Clinical and neuropsychological characteristics in familial and sporadic Alzheimer's disease: relation to apolipoprotein E polymorphism. Neurology 1996; 46: 413-419.

29 McKhann G, Drachman D, Folstein M, Katzman R, Price D, Stadlan EM: Clinical diagnosis of Alzheimer's disease: report of the NINCDS-ADRDA Work Group under the auspices of Department of Health and Human Services Task Force on Alzheimer's Disease. Neurology 1984; 34: 939-944.

30 Mirra SS, Heyman A, McKeel D et al: The Consortium to Establish a Registry for Alzheimer's Disease (CERAD). Part II. Standardization of the neuropathologic assessment of Alzheimer's disease. Neurology 1991; 41: 479-486.

31 Hixon JE, Vernier DT: Restriction isotyping of human apolipoprotein E by gene amplification and cleavage with HhaI. J Lipid Res 1990; 31: 545-548.

32 Raymond ML, Rousset F: An exact test for population differentiation. Evolution 1995; 49: 1280-1283.

33 Lambert JC, Harris JM, Mann D et al: Are the estrogen receptors involved in Alzheimer's disease? Neurosci Lett 2001; 306: 193-197.

34 Osterlund MK, Gustafsson JA, Keller E, Hurd YL: Estrogen receptor beta (ERbeta) messenger ribonucleic acid (mRNA) expression within the human forebrain: distinct distribution pattern to ERalpha mRNA. J Clin Endocrinol Metab 2000; 85: 3840-3846.

35 Fitzpatrick JL, Mize AL, Wade CB, Harris JA, Shapiro RA, Dorsa DM: Estrogen-mediated neuroprotection against beta-amyloid toxicity requires expression of estrogen receptor alpha or beta and activation of the MAPK pathway. I Neurochem 2002; 82: $674-682$.

36 Mize AL, Shapiro RA, Dorsa DM: Estrogen receptor-mediated neuroprotection from oxidative stress requires activation of the mitogen-activated protein kinase pathway. Endocrinology 2003; 144: 306-312.

37 Zhao L, Wu TW, Brinton RD: Estrogen receptor subtypes alpha and beta contribute to neuroprotection and increased Bcl-2 expression in primary hippocampal neurons. Brain Res 2004; 1010: $22-34$.

38 Savaskan E, Olivieri G, Meier F, Ravid R, Muller-Spahn F: Hippocampal estrogen beta-receptor immunoreactivity is increased in Alzheimer's disease. Brain Res 2001; 908: $113-119$.

39 Zhang $\mathrm{QH}$, Huang $\mathrm{YH}, \mathrm{Hu} \mathrm{YZ}$ et al: Disruption of estrogen receptor beta in mice brain results in pathological alterations resembling Alzheimer disease. Acta Pharmacol Sin 2004; 25: $452-457$.

40 Ogawa S, Emi M, Shiraki M, Hosoi T, Ouchi Y, Inoue S: Association of estrogen receptor beta (ESR2) gene polymorphism with blood pressure. J Hum Genet 2000; 45: 327-330.

41 Zhu Y, Bian Z, Lu P et al: Abnormal vascular function and hypertension in mice deficient in estrogen receptor beta. Science 2002; 295: 505-508.

42 Kivipelto M, Helkala EL, Laakso MP et al: Midlife vascular risk factors and Alzheimer's disease in later life: longitudinal, population based study. BMJ 2001; 322: 1447-1451. 